\title{
Trends in the prevalence of smoking in Portugal: a systematic review
}

Helena Carreira ${ }^{1,2^{*}}$, Marta Pereira ${ }^{1,2}$, Ana Azevedo ${ }^{1,2}$ and Nuno Lunet ${ }^{1,2}$

\begin{abstract}
Background: Understanding the dynamics of smoking at the population level is essential for the planning and evaluation of prevention and control measures. We aimed to describe trends in the prevalence of smoking in Portuguese adults by sex, age-group and birth cohort.

Methods: PubMed was searched from inception up to 2011. Linear regression was used to assess differences in prevalence estimates according to the type of population sampled, and to estimate time trends of smoking prevalence considering only the results of studies on nationally representative samples of the general population.

Results: Thirty eligible studies were identified. There were statistically significant differences in the prevalence estimates according to the types of population sampled in the original studies. Between 1987 and 2008, the prevalence of smoking increased significantly among women aged $\leq 70$ years; the steepest increase was observed in those aged $31-50$ and $51-70$ years (from $4.6 \%$ and $0.1 \%$ in 1988, respectively, to $16.4 \%$ and $4.5 \%$ in 2008 , respectively). The prevalence of smoking increased in all birth cohorts, except for those born before 1926. In the same period, among men, smoking decreased in all age-groups, with steepest declines in those aged $\leq 30$ years (from $41.8 \%$ in 1988 to $28.8 \%$ in 2008) and those aged $\geq 71$ years (from 15.1\% in 1988 to $4.6 \%$ in 2008). The prevalence of smoking declined among men of all birth cohorts.
\end{abstract}

Conclusions: This study provides robust evidence to place Portuguese women at stage II and men at the later stages of the tobacco epidemic.

Keywords: Epidemiology, Portugal, Smoking, Trends

\section{Background}

Smoking is the main preventable cause of premature death [1]. In 2004, it caused nearly 5 million deaths worldwide, accounting for approximately $25 \%$ and $7 \%$ of the mortality among adult European men and women, respectively [2]. In Portugal, in 2005, it was estimated that $18 \%$ of the deaths in men and $5 \%$ in women were attributable to smoking, accounting for more than 70 thousand disability-adjusted life years [3].

The most comprehensive data on smoking in Portugal comes from the four National Health Surveys [4-7] and from several Eurobarometer surveys [8-14]. However, most of the latter did not provide sex- and age-specific

\footnotetext{
*Correspondence: hcarreira@med.up.pt
'Department of Clinical Epidemiology, Predictive Medicine and Public Health,

*Correspondence: hcarreira@med.up.pt
'Department of Clinical Epidemiology, Predictive Medicine and Public Health, University of Porto Medical School, Al. Prof. Hernâni Monteiro, Porto 4200-319, Portugal

${ }^{2}$ Institute of Public Health of the University of Porto, Rua das Taipas, no 135,

Porto 4050-600, Portugal
}

estimates, which are essential to plan, monitor and evaluate the impact of prevention and control measures. Other studies assessed smoking behaviours in different calendar years, mainly from smaller regional samples recruited across the country, but the usefulness of these estimates has not been systematically addressed before.

A general model for the tobacco epidemic is widely accepted [15], though not all countries followed the same pattern as the ones used to formulate this model a few decades ago [16]. Country-specific data on the patterns of smoking at a population level are, therefore, necessary to understand its dynamics in each setting.

We conducted a comprehensive systematic review of studies that quantified the prevalence of smoking in Portuguese adults. Our specific aims were to compare the estimates obtained from studies that evaluated populations with different characteristics and to estimate the 
trends in the prevalence of smoking in Portugal, by sex, age-group and birth cohort.

\section{Methods}

\section{Search strategy}

We searched PubMed from inception up to January 2011, to identify original studies and review articles addressing the distribution of smoking in samples of the Portuguese adult population. The detailed search expression is presented in the systematic review flowchart (Additional file 1: Figure S1). This is a comprehensive search expression that includes terms directly related with smoking behaviours ("smoking", "smoke", "tobacco", "cigarette"), as well as with other cardiovascular risk factors (hypertension, obesity, dyslipidaemia, diabetes, physical inactivity). The latter were also included because smoking is frequently associated with other behaviours with potential impact in human health $[17,18]$, and therefore reports with primary objectives not directly related with the assessment of smoking behaviours may also provide data of interest for this review, as secondary results. The reference lists of the review articles addressing the distribution of cardiovascular risk factors were screened to identify potentially eligible original reports. Additionally, we searched for reports that are by nature not suitable for indexation in journal databases (e.g. Eurobarometer study).

\section{Eligibility criteria and screening of reference lists}

Two reviewers independently evaluated the studies in three consecutive steps, following predefined criteria, to determine the eligibility of each report. The first two steps relied on the same criteria. In step 1 , the exclusion of irrelevant studies was decided by considering only the title and abstract; when the abstract of a particular article was not available, the article was selected for evaluation in step 2, except when the title unequivocally presented information for exclusion (e.g. case report, studies of risk factors in a specified population). The full text of studies selected for step 2 were then evaluated to decide on their eligibility. The studies selected for step 3 were reevaluated to determine their adequacy for extraction of relevant data.

The criteria for exclusion of studies were the following: reports not written in Portuguese, English, Spanish, French or Italian; studies not involving humans (e.g. in vitro or animal research); editorials, reviews or comments; reports not providing data specifically for Portuguese subjects; studies not evaluating adult populations; studies in which sample selection was dependent of at least one cardiovascular risk factor (hypertension, obesity, dyslipidaemia, diabetes or physical inactivity) and therefore participants could not represent the general population regarding the prevalence of smoking (e.g. subjects with diabetes, athletes, sedentary elderly); insufficient characterization of the methods (e.g. not specifying the region where the sample was assembled); not presenting sex-specific data on smoking. We did not exclude from the systematic review the studies presenting data not stratified by age, although these were not eligible for all data synthesis.

When more than one report referred to the same study, we considered the one providing data for the largest sample or, when the sample was the same, we used the source presenting the results with more detail, although any of these reports could be used to obtain information on the study characteristics.

The disagreements between the independent assessments of the reviewers were resolved by consensus or after discussion with a third researcher.

\section{Data extraction}

Two investigators independently evaluated the selected studies to extract the following data for sample characterization: sex; age; sample size; type of population (general population, university students, occupational groups, users of primary health care centers or volunteers); sampling strategy (probability or non probability sampling); geographical coverage (national or regional).

We considered the study population to be general population when subjects were randomly selected from the electoral rolls or recruited from the registries of the primary health care centers. The latter were considered general population because in Portugal the access to the National Health Service is universal and in theory everyone is registered, including those who do not use it as the main source of health care. The studies that evaluated samples of the general population were further divided according to the geographical coverage of the study, into regional or national representative samples. University students, occupational groups, users of primary health care centers (when subjects were recruited among the attendants to health care centers or data were abstracted from clinical records) and volunteers (when subjects took some initiative to participate in the survey) were considered different types of population.

We extracted age-specific prevalence estimates of current smoking, whenever available. Due to the large heterogeneity in the criteria to define classes of smoking, we considered that the data referred to current smoking when described in the original reports as: "currently smoking"; "currently smoking or had ceased for less than one year"; "smoking cigarettes but not as many as one per day, or smoking more than one cigarette per day, or smoking pipe or cigars"; "regular smoking"; "smoking daily"; "smoking daily for at least six months".

The mean age of each age-group was extracted, whenever available. For the studies that did not present the 
mean age of the participants in each age-group we assumed the mid-point of the age interval; for the open age intervals at the extremes we estimated the mid-point by adding and subtracting the width of the closest class to the upper and to the lower limits, respectively (e.g. for surveys reporting data in participants aged < 30, 30-39, $40-49$, and $\geq 50$ years, we considered the overall range as 20-59 years). When an age-group also included subjects aged below 18 years old (e.g. 17-20 years), we computed the mid-point and excluded the data if the mid-point year was lower than 17.5 years old.

We obtained age- and sex-specific estimates directly from the authors of three studies [7,19,20], including one of the largest regional surveys and two national surveys.

Differences in the data extracted by the two investigators were discussed until consensus, and involving a third investigator whenever necessary.

\section{Data analysis}

We compared the estimates of current smoking across the different types of population, considering national representative samples of the general population as the reference class. To quantify these differences, we fitted sex-specific multiple linear regression models, adjusting for the mean age of the participants (continuous variable), the year of survey (continuous variable), the smoking measure involved (daily smoking/current smoking, categorical variable) and geographical coverage of the study (national/regional, categorical variable). Since more than one estimate of the smoking prevalence could be extracted from each report, corresponding to different age strata, the confidence intervals derived from the multiple linear regression models were calculated using robust estimates of the standard errors [21], to account for the dependence between the observations from the same study.

To estimate the time trends of the prevalence of smoking, we considered only the results of the studies that evaluated samples with national coverage that were representative of the general population [14,20,22-24]. We conducted sex-specific stratified analyses for four agegroups and according to birth cohorts. We selected the age-groups $\leq 30,31-50,51-70$ and $>70$ to represent young, young middle aged, middle aged and older subjects.

As some of the studies included in the review evaluated samples of subjects in a wide range of ages, and therefore the estimated mid-point of the age-group may not correspond to an accurate estimation of the age of a large proportion of the subjects evaluated, we excluded the results of these studies from the time trends analyses $[14,24]$.

To compute the year of birth of the participants, we subtracted the mid-point age of each age-group from the calendar year of the survey. This variable was further categorized using the quartiles of the distribution as cutoffs: $\leq 1926$; 1927-1946; 1947-1959; $\geq 1960$.

The results are presented in figures, describing the sex-specific variation of the smoking prevalence over time for each age group and birth cohort. We included in the figures only one estimate per age-group from each study. When studies reported estimates by strata of age that were narrower than the age-agroups we defined for analysis, it corresponded to the average of the prevalence in the narrower age strata, weighted by the corresponding number of participants. Each figure also includes a line representing the linear or quadratic (whenever significantly different from the linear) prediction of the prevalence of current smoking as a function of the year of survey.

We also provide estimates of the prevalence of smoking obtained from the linear regression models in selected calendar years, for each age-group and birth cohort.

\section{Results}

\section{Systematic review}

Thirty studies were eligible for the systematic review. Detailed information on their main characteristics, as well as the respective prevalence estimates, are provided in the Additional file 1: Table S1. The reports were published between 1990 and 2012, and referred to data collected between 1987 and 2012.

Estimates of current smoking in women and in men were available from 26 and 28 reports, respectively, 8 of which evaluated mainland/national samples. The studies were conducted in 5 different types of population, including general population ( $n=14)$, occupational groups $(n=3)$, university students $(n=6)$, users of primary health care centers $(\mathrm{n}=6)$ and volunteers $(\mathrm{n}=1)$ (Additional file 1 : Table S1).

\section{Estimates of the prevalence of current smoking according to the type of population}

Having as reference the results from the 6 studies that evaluated national samples of the general population and provided age-stratified estimates, the prevalence of current smoking among women, adjusted for the age of the participants, year of survey and measure of smoking involved, was significantly higher in primary health care users [4.6\%; 95\% confidence interval (95\% CI): 2.1 to 7.0]. Among men, the prevalence of current smoking was significantly higher in regional samples of the general population (7.0\%; $95 \% \mathrm{CI}: 0.1$ to 13.4 ) and primary health care centres users (5.3\%; 95\% CI: 2.7 to 7.9 ); it was significantly lower in samples of specific occupational groups (-12.5\%; 95\% CI: -16.2 to -8.8$)$, volunteers $(-7.5 \%$; $95 \%$ CI: -8.9 to -6.1$)$ and university students (-13.4\%; $95 \%$ CI: -24.5 to -2.4$)$ independently of the age 
of the participants, survey year and measure involved to define smoking (Figure 1).

Trends in smoking prevalence in the general population Between 1988 and 2008, the prevalence of current smoking increased significantly among women of all ages, except in those older than 70 years (Figure 2). The steepest increase was observed in those aged 3150 years and $51-70$ years (from $4.6 \%$ and $0.1 \%$ in 1988 , respectively, to $16.4 \%$ and $4.5 \%$ in 2008 , respectively); a less pronounced upward trend was reported in younger women (Figure 2 and Table 1). The prevalence of smoking increased in all cohorts, except in women born before 1926, though the absolute variation was much smaller than the observed in the analysis by age-group (Figure 3 and Table 1).

In the same 20 year-period, the prevalence of smoking among men decreased in all age-groups, with steepest declines observed among those aged $\leq 30$ years (from $41.8 \%$ in 1988 to $28.8 \%$ in 2008) and those aged $\geq 71$ years (from $15.1 \%$ in 1988 to $4.6 \%$ in 2008) (Figure 2 and Table 1). The prevalence of smoking has declined linearly among men born between 1927 and 1946, and in those born after 1960. For the cohorts of men born before 1926, the prevalence decreased, mainly before 1995, and stabilized thereafter, while among those born between 1947 and 1959 a steep decline was observed only in the second half of the period of analysis (Figure 3).

\section{Discussion}

This study shows that in the last decades the smoking prevalence increased markedly among Portuguese women, while it decreased among men. The results from the studies involving samples of the general population without national representativeness overestimate the national prevalence of smoking, showing that these studies are of limited interest when the purpose is to estimate time trends in the general population.

Smoking is strongly associated with morbidity, and the lower prevalence observed in the samples of specific occupational groups may result from selection bias, as subjects need to be healthy enough to be active workers and those who develop diseases are more likely to leave their employment [25]. Among workers, smoking has also been associated with greater absenteeism and

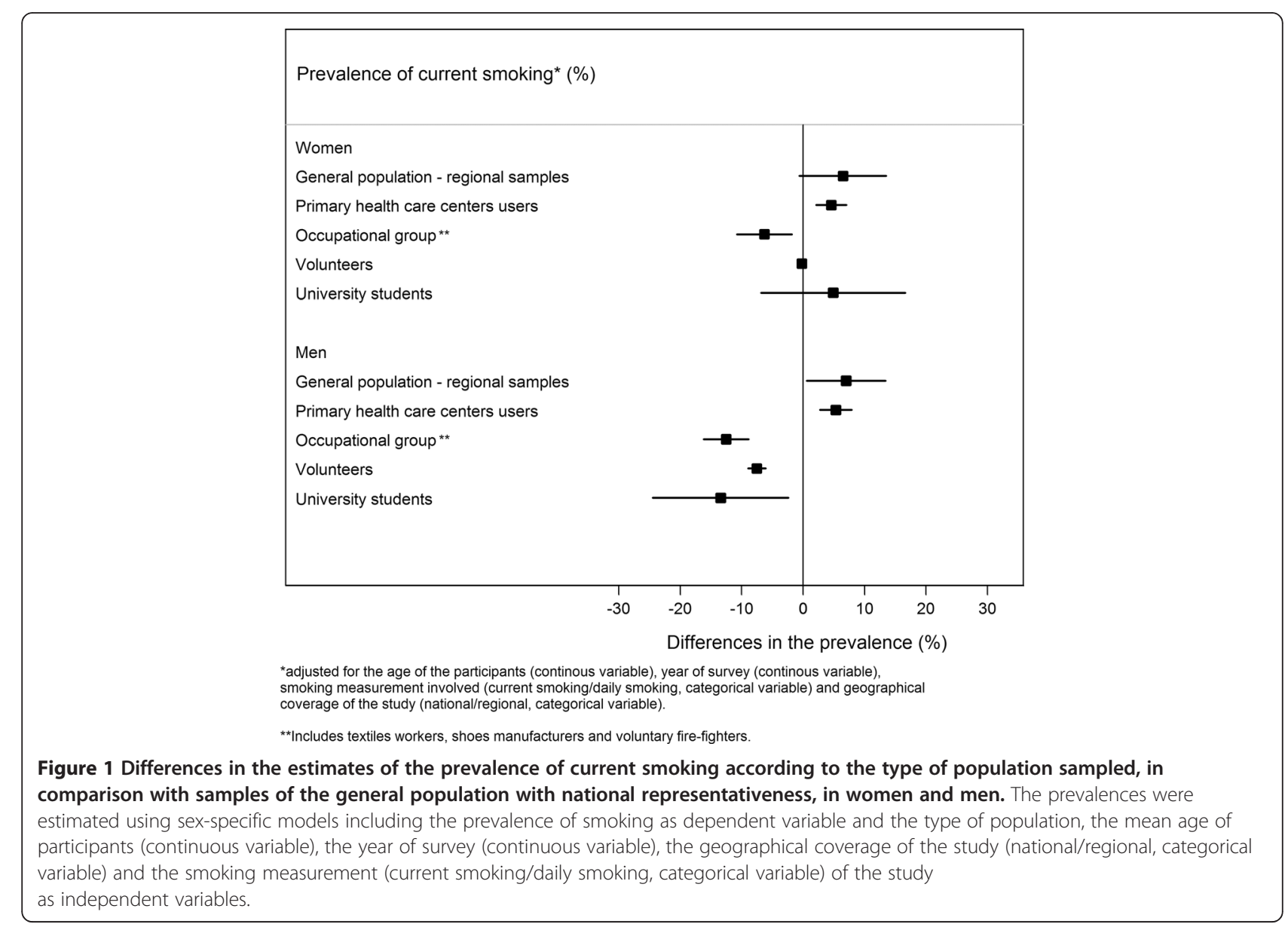



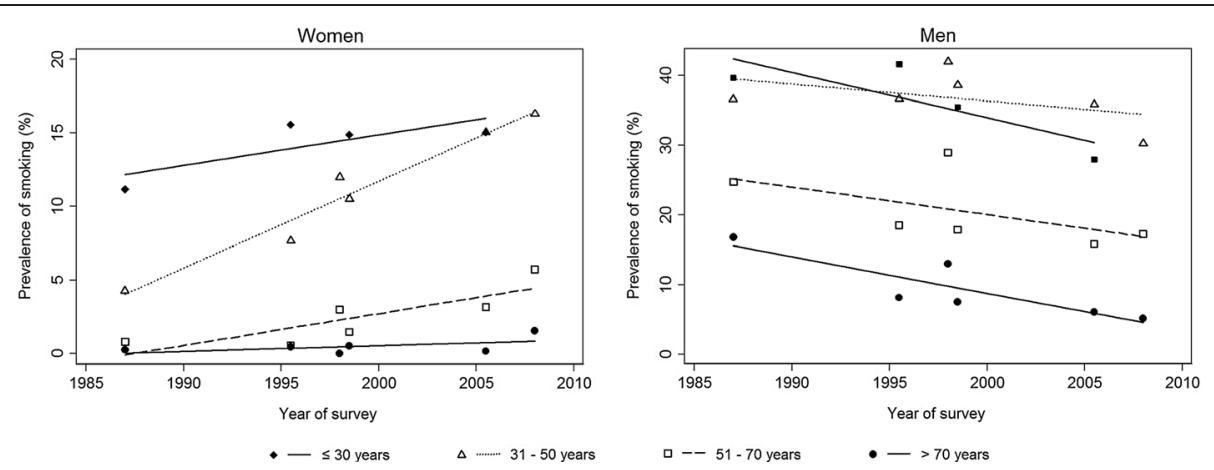

Figure 2 Trends in the prevalence of smoking in different age group, by sex. Only were considered the results of the studies involving national representative samples of the general population. When a given study provided more than one estimate for each of the age groups computed, we computed the weighted mean of the prevalence of smoking. Studies involving samples with a wide age-range and not presenting age-stratified data were excluded.

injuries [26,27], which contributes to a lower probability of smokers being selected for the epidemiological investigations.

In the only study whose participants we considered volunteers, the healthy volunteer effect is likely to have occurred, as those who have a proactive attitude to participate in a survey tend to be more sensitive to health messages than the average person from the general population $[28,29]$.

Primary health care users had significantly higher levels of smoking, both in women and in men. Smoking is strongly associated with a higher incidence of several chronic diseases [30,31] and the prevalence estimates for this group may reflect the increased use of health care services by smokers.

The gender differences in the prevalence of smoking among university students are likely to be explained by Portuguese women being at earlier stages of the smoking epidemic than men.

According to the most recent update of the smoking epidemic model [16], among women the stage II is characterized by a rapid increase of the prevalence of smoking, along with few deaths attributable to smoking; stage III starts when the peak prevalence is achieved. Our results on the trends in the prevalence of smoking place Portuguese women in the second stage of the epidemic $[15,16]$. However, between 1955 and 2005, the lung cancer mortality rates increased 1.6\% (95\% CI: $1.4 \%-1.8 \%$ ) per year among Portuguese women (35-74 years) [32], which is compatible with both the end of stage II and stage III of the smoking epidemic.

The data referring to men suggest an ongoing transition from the third to the fourth phase of the smoking epidemic. In phase III, the prevalence of smoking begins to decline, while the smoking-attributable mortality rises rapidly $[15,16]$. In phase IV, the prevalence continues to decline while the mortality attributable to smoking peaks in the beginning of this stage and declines thereafter $[15,16]$. Among Portuguese men aged 35 to 74 years, between 1986 and 1996, the annual percent change (APC) in the lung cancer mortality rate was $1.52 \%$ (95\% CI: $0.59 \%$ to $2.46 \%$ ), and between 1996 and 2005 the rates stabilized (APC: $-0.15 \%, 95 \%$ CI: $-0.99 \%$ to $0.69 \%$ ) [32].

Previous studies involving cross-sectional analyses have placed Portugal at earlier stages of the epidemic than most European countries [23,33]; Spain, the neighbour country, is at the beginning of stage IV [34]. We put forward a sexspecific classification for the Portuguese population, in
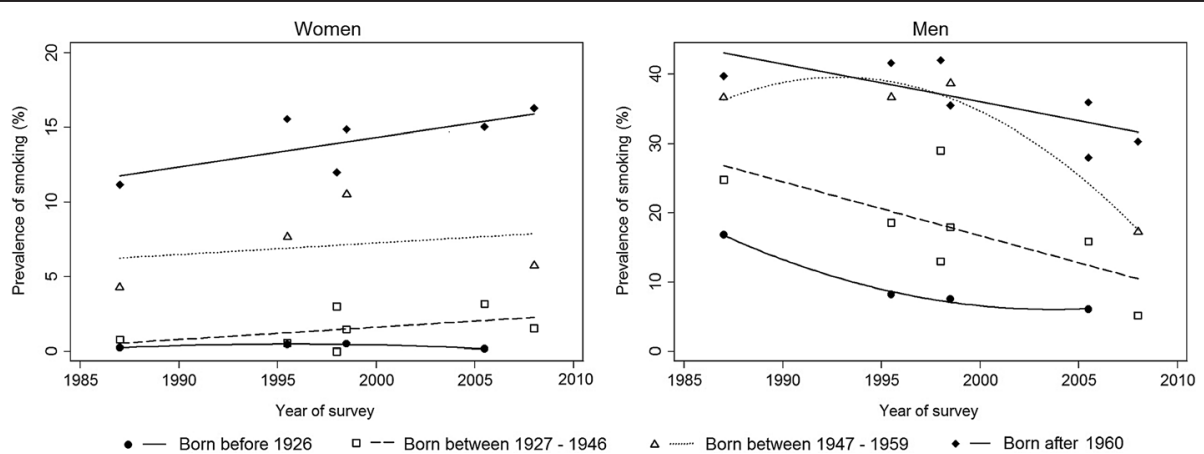

Figure 3 Trends in the prevalence of smoking in different birth cohorts, by sex. 
Table 1 Estimated prevalence of smoking by age group and birth cohort

\begin{tabular}{|c|c|c|c|c|c|c|}
\hline & \multicolumn{6}{|c|}{ Estimated prevalence of smoking (\%) and $95 \%$ confidence intervals * } \\
\hline & \multicolumn{3}{|c|}{ Women } & \multicolumn{3}{|c|}{ Men } \\
\hline & $1988+$ & $1998+$ & $2008+$ & $1988+$ & $1998+$ & $2008+$ \\
\hline \multicolumn{7}{|l|}{ Age group } \\
\hline$\leq 30$ years & $12.4(8.3$ to 16.5$)$ & $14.4(12.0$ to 16.9$)$ & 15.9 (12.4 to 19.3$)$ & $41.8(30.6$ to 52.9$)$ & $35.3(28.7$ to 41.9$)$ & $28.8(18.0$ to 39.7$)$ \\
\hline $31-50$ years & $4.6(3.0$ to 6.3$)$ & 10.5 (9.4 to 11.6$)$ & 16.4 (15.7 to 17.2$)$ & $39.3(32.2$ to 46.4$)$ & 36.9 (32.9 to 40.8$)$ & $34.4(27.4$ to 41.5$)$ \\
\hline $51-70$ years & $0.1(0.0$ to 2.4$)$ & $2.3(1.0$ to 3.5$)$ & $4.5(2.2$ to 6.7$)$ & $24.8(18.7$ to 30.9$)$ & 20.9 (15.9 to 25.9$)$ & 16.9 (12.2 to 21.6) \\
\hline$\geq 71$ years & 0.1 (0.0 to 0.7 ) & 0.5 (0.2 to 1.0$)$ & 0.9 (0.0 to 2.1) & 15.1 (10.9 to 19.3$)$ & 9.9 (7.2 to 12.6$)$ & 4.6 (2.4 to 6.8) \\
\hline \multicolumn{7}{|l|}{ Birth cohort } \\
\hline$\leq 1926$ & 0.3 (0.0 to 1.0 ) & 0.5 (0.1 to 1.0$)$ & 0.0 (0.0 to 1.2 ) & 15.5 (8.5 to 22.5$)$ & $7.3(1.5$ to 13.1$)$ & $6.8(0.0$ to 19.3$)$ \\
\hline $1927-1946$ & 0.6 (0.0 to 2.8$)$ & 1.5 (0.3 to 2.6$)$ & 2.3 (0.3 to 4.3$)$ & 26.1 (14.3 to 37.8) & 18.3 (12.3 to 24.3$)$ & 10.5 (0.0 to 21.2$)$ \\
\hline $1947-1959$ & 6.3 (0.0 to 17.3$)$ & $7.1(0.2$ to 14.0$)$ & 7.9 (0.0 to 19.9$)$ & 37.3 (3.1 to 71.4) & 37.0 (8.3 to 65.8$)$ & 17.5 (0.0 to 57.0$)$ \\
\hline$\geq 1960$ & 12.0 (9.3 to 14.7$)$ & 13.9 (12.5 to 15.3$)$ & 15.9 (13.8 to 18.1$)$ & 42.5 (34.6 to 50.4$)$ & 37.1 (33.0 to 41.1) & 31.6 (25.4 to 37.9$)$ \\
\hline
\end{tabular}

accordance with the recent review of the smoking epidemic model [16]. The earlier stage proposed for women might be a consequence of Portugal's lower economic and social development, which may have determined a slower spread of the epidemic among the less educated women who are particularly affected by prices increases [35,36]. Portugal may take advantage of this position among women, by implementing effective public health measures to curb the trends observed and to avoid the harmful effects of smoking in the next decades.

The present review is based on an extensive literature search and provides a comprehensive summary of the best available evidence on the prevalence of smoking in Portugal. However, there are some limitations that need to be addressed.

The studies included in the systematic review are heterogeneous in what concerns the criteria to define smoking, involving measures of current and daily smoking, possibly contributing to an underestimation of the smoking prevalence and trends in Portugal. However, there were no statistically significant differences according to the criteria involved and a sensitivity analysis that excluded the studies only providing data on daily smoking yielded virtually the same results.

Another limitation of this study results from the inclusion of samples of subjects aged above 18 years, while the smoking behaviours of the population aged above 15 years are important for a more comprehensive understanding of the dynamics of smoking and the tobacco epidemic.

Portugal signed the World Health Organization Framework Convention on Tobacco Control and already adopted measures to control tobacco consumption. These include health warnings in the cigarette packages, tax increases and, more recently, a law regulating the use of tobacco in restaurants and other public places, aiming to protect subjects from passive smoking exposure [37]. The strict enforcement of the latter measure occurred in 2008 and may have had a greater impact on the smoking behaviours of the population. However, we only obtained age-stratified data on the smoking prevalence until 2008 and therefore the impact of this measure could not be ascertained in the present study.

After 1998, the smoking prevalence has been declining among all birth cohorts of men. This is in accordance with the decreasing sales of tobacco products in Portugal, which were estimated to be nearly 18 billion cigarettes in 2002, and less than 12 billion in 2011 [38]. Notwithstanding, the trends reported in this study, especially among women, demand for the reinforcement of the existing policies and for more effective policies targeting the whole population. In Portugal the percentage of per capita gross domestic product needed to purchase 100 packs of cigarettes was 1.66 in 1990 and 1.76 in 2006, representing a small change in the cigarettes affordability in the country over the last decades [39]. Price increases have been associated with reduced consumption and quitting smoking [40], and tax increases may be particularly important in the current local scenario of economic and financial crisis. Furthermore, they have the potential to affect particularly lower socio-economic groups, among whom the prevalence of smoking is higher in men [23] and expected to increase among women [19]. Other measures, such as the promotion of the smoking cessation clinics already existing in the country and the creation of new ones, as well as the free provision of nicotine-replacement therapies and other similar aids, may contribute to downward trends [41]. The monitoring of the epidemic should also consider the study of other tobacco products expected to be 
increasingly used with the rising prices and decreasing purchasing power [40].

\section{Conclusions}

Our results place Portuguese women in the stage II of the smoking epidemic, while men are at the later stages, between stages III and IV.

\section{Additional file}

Additional file 1: Figure S1. Systematic review flowchart. The studies identified through PubMed search and screening of the bibliographic references of the review articles were evaluated independently by two researchers, in three consecutive steps, following pre-defined criteria. Thirty studies, from five distinct type of population, were eligible for systematic review. Table S1 Main characteristics and results of the studies included in the systematic review and respective prevalence estimates.

\section{Competing interests}

The authors declare that they have no competing interests.

\section{Authors' contributions}

$\mathrm{HC}$ collaborated in the acquisition, analysis and interpretation of the data, and wrote the first draft of the article. MP collaborated in the design of the study, data collection and revision of the article. AA and NL designed the study, analyzed and interpreted the data, and reviewed the article critically for important intellectual content. All authors read and approved the final manuscript.

\section{Acknowledgements}

The authors gratefully acknowledge the collaboration of Catarina Vales and Vânia Rocha for the participation in the screening of reference lists and data extraction. This work was supported by two grants from Fundação para a Ciência e a Tecnologia (PIC/IC/83006/2007 and PTDC/SAU-EPI/122460/2010). The funding source had no influence on study design, data collection and analysis, report of results or on the decision to submit the manuscript for publication.

\section{Received: 29 June 2012 Accepted: 22 October 2012}

Published: 8 November 2012

\section{References}

1. World Health Organization: WHO report on the global tobacco epidemic, 2011: warning about the dangers of tobacco. Geneva: World Health Organization; 2011.

2. World Health Organization: WHO global report: mortality attributable to tobacco. Geneva: World Health Organization; 2012.

3. Borges M, Gouveia M, Costa J, Dos Santos Pinheiro L, Paulo S, Vaz Carneiro A: The burden of disease attributable to smoking in Portugal. Rev Port Pneumol 2009, 15:951-1004.

4. Instituto Nacional de Estatística: Inquérito Nacional de Saúde, 1987. Lisboa: Ministério da Saúde - Departamento de Estudos e Planeamento da Saúde; 1989.

5. Instituto Nacional de Estatística: Inquérito Nacional de Saúde, 1995-1996. Lisboa: Ministério da Saúde - Departamento de Estudos e Planeamento da Saúde; 1999.

6. Instituto Nacional de Estatística: Inquérito Nacional de Saúde, 1998-1999. Lisboa: Ministério da Saúde - Departamento de Estudos e Planeamento da Saúde; 2000.

7. Instituto Nacional de Estatística, Instituto Nacional de Saúde Ricardo Jorge: Inquérito Nacional de Saúde, 2005-2006. Lisboa: Ministério da Saúde - Departamento de Estudos e Planeamento da Saúde; 2009.

8. Comission of the European Communities: Europeans and cancer prevention. Food consumption habits, smoking and cancer screening for women. In Book Europeans and cancer prevention. Food consumption habits, smoking and cancer screening for women; 1988.
9. European Comission - Eurobarometer - Public opinion in European Union: Report on Standard Eurobarometer 43. In Book Report on Standard Eurobarometer 43; 1995.

10. European Comission: Smoking and the environment: actions and attitudes. Special Eurobarometer 183/Wave 58.2 - European Opinion Research Group EEIG. In Book Smoking and the environment: actions and attitudes. Special Eurobarometer 183/Wave 58.2 - European Opinion Research Group EEIG; 2003.

11. European Comission: Attitudes of Europeans towards tobacco. pecial Eurobarometer 239/Waves 64.1 - 64.3. In Book Attitudes of Europeans towards tobacco. pecial Eurobarometer 239/Waves 64.1 - 64.3. 2006.

12. European Comission: Survey on tobacco - analytical report. Flash Eurobarometer 253 - The Gallup Organisation. In Book Survey on Tobacco - Analytical report. Flash Eurobarometer 253 - The Gallup Organisation. 2009

13. European Comission: Tobacco. Special Eurobarometer 332/Wave 72.3 In Book Tobacco. Special Eurobarometer 332/Wave 72.3; 2010.

14. European Comission: Attitudes of Europeans towards tobacco. Special Eurobarometer 385/Wave EB77.1. In Book Attitudes of Europeans Towards Tobacco. Special Eurobarometer 385/Wave EB77.1; 2012.

15. Lopez AD, Collishaw NE, Piha T: A descriptive model of the cigarette epidemic in developed countries. Tob Control 1994, 3:242-247.

16. Thun M, Peto R, Boreham J, Lopez AD: Stages of the cigarette epidemic on entering its second century. Tob Control 2012, 21:96-101.

17. Padrao P, Lunet N, Santos AC, Barros H: Smoking, alcohol, and dietary choices: evidence from the Portuguese National Health Survey. BMC Public Health 2007, 7:138.

18. Padrao P, Silva-Matos C, Damasceno A, Lunet N: Association between tobacco consumption and alcohol, vegetable and fruit intake across urban and rural areas in Mozambique. J Epidemiol Community Health 2011, 65:445-453.

19. Santos $A C$, Barros $H$ : Smoking patterns in a community sample of Portuguese adults, 1999-2000. Prev Med 2004, 38:114-119.

20. Correia S, Dinis P, Rolo F, Lunet N: Prevalence, treatment and known risk factors of urinary incontinence and overactive bladder in the non-institutionalized Portuguese population. Int Urogynecol J Pelvic Floor Dysfunct 2009, 20:1481-1489.

21. StataCorp: Robust variance estimates. In Stata: Release 11 Statistical Software. College Station. TX: StataCorp LP; 2009.

22. Precioso J, Calheiros J, Pereira D, Campos H, Antunes H, Rebelo L, Bonito J: [Prevalence and smoking trends in Portugal and Europe]. Acta Med Port 2009, 22:335-348.

23. Huisman M, Kunst $A E$, Mackenbach JP: Educational inequalities in smoking among men and women aged 16 years and older in 11 European countries. Tob Control 2005, 14:106-113.

24. Cardoso C, Plantier T: Acompanhamento estatístico e epidemiológico do consumo de tabaco em Portugal. Estudo do impacte da Lei n. $37 / 2007$, de 14 de Agosto. In Book Acompanhamento estatístico e epidemiológico do consumo de tabaco em Portugal. Estudo do impacte da Lei n. ${ }^{\circ}$ 37/2007, de 14 de Agosto; 2008.

25. Li CY, Sung FC: A review of the healthy worker effect in occupational epidemiology. Occup Med (Lond) 1999, 49:225-229.

26. Ryan J, Zwerling C, Orav EJ: Occupational risks associated with cigarette smoking: a prospective study. Am J Public Health 1992, 82:29-32.

27. Sacks JJ, Nelson DE: Smoking and injuries: an overview. Prev Med 1994, 23:515-520.

28. Croswell JM, Ransohoff DF, Kramer BS: Principles of cancer screening: lessons from history and study design issues. Semin Oncol 2010, 37:202-215.

29. Lindsted KD, Fraser GE, Steinkohl M, Beeson WL: Healthy volunteer effect in a cohort study: temporal resolution in the Adventist Health Study. J Clin Epidemiol 1996, 49:783-790.

30. Cena H, Fonte ML, Turconi G: Relationship between smoking and metabolic syndrome. Nutr Rev 2011, 69:745-753.

31. Teo KK, Ounpuu S, Hawken S, Pandey MR, Valentin V, Hunt D, Diaz R, Rashed W, Freeman R, Jiang $L$, et al: Tobacco use and risk of myocardial infarction in 52 countries in the INTERHEART study: a case-control study. Lancet 2006, 368:647-658.

32. Alves $L$, Bastos J, Lunet N: Trends in lung cancer mortality in Portugal (1955-2005). Rev Port Pneumol 2009, 15:575-587. 
33. Cavelaars AE, Kunst AE, Geurts JJ, Crialesi R, Grotvedt L, Helmert U, Lahelma $\mathrm{E}$, Lundberg O, Matheson J, Mielck A, et al: Educational differences in smoking: international comparison. BMJ 2000, 320:1102-1107.

34. Regidor E, Gutierrez-Fisac JL, de los Santos Ichaso M, Fernandez E: Trends in principal cancer risk factors in Spain. Ann Oncol 2010, 21(Suppl 3):iii37-iii42.

35. Giskes K, Kunst AE, Benach J, Borrell C, Costa G, Dahl E, Dalstra JA, Federico B, Helmert U, Judge K, et al: Trends in smoking behaviour between 1985 and 2000 in nine European countries by education. J Epidemiol Community Health 2005, 59:395-401.

36. Schaap MM, Kunst AE, Leinsalu M, Regidor E, Espelt A, Ekholm O, Helmert U, Klumbiene J, Mackenbach JP: Female ever-smoking, education, emancipation and economic development in 19 European countries. Soc Sci Med 2009, 68:1271-1278.

37. Lei no 37/2007 de 14 de Agosto de 2007: Aprova normas para a protecção dos cidadãos da exposição involuntária ao fumo do tabaco e medidas para a redução da procura relacionada com a dependência e a cessação do seu consumo. Diário da república, (1a série - № 156).

38. European Commission. Taxation and Customs Union. Manufactured tobacco: Excises duty rates. Releases for consumption of cigarettes 2002-2011.

Available at: http://ec.europa.eu/taxation_customs/taxation/excise_duties/ tobacco_products/rates/index_en.htm.

39. Blecher EH, van Walbeek CP: Cigarette affordability trends: an update and some methodological comments. Tob Control 2009, 18:167-175.

40. Hanewinkel $R$, Isensee B: Five in a row-reactions of smokers to tobacco tax increases: population-based cross-sectional studies in Germany 2001-2006. Tob Control 2007, 16:34-37.

41. Kunst A, Giskes K, Mackenbach J: Socio-economic inequalities in smoking in the European Union. Applying an equity lens to tobacco control policies. Brussels: European Network of Smoking Prevention; 2004.

doi:10.1186/1471-2458-12-958

Cite this article as: Carreira et al:: Trends in the prevalence of smoking in Portugal: a systematic review. BMC Public Health 2012 12:958.

\section{Submit your next manuscript to BioMed Central and take full advantage of:}

- Convenient online submission

- Thorough peer review

- No space constraints or color figure charges

- Immediate publication on acceptance

- Inclusion in PubMed, CAS, Scopus and Google Scholar

- Research which is freely available for redistribution

Submit your manuscript at www.biomedcentral.com/submit
() Biomed Central 